\title{
Neural correlates of emotional intelligence in adolescent children
}

\author{
William D. S. Killgore and Deborah A. Yurgelun-Todd \\ McLean Hospital, Harvard Medical School, Belmont, Massachusetts
}

\begin{abstract}
The somatic marker hypothesis posits a key role for the ventromedial prefrontal cortex, amygdala, and insula in the ability to utilize emotions to guide decision making and behavior. However, the relationship between activity in these brain regions and emotional intelligence (EQ) during adolescence, a time of particular importance for emotional and social development, has not been studied. Using functional magnetic resonance imaging (fMRI), we correlated scores from the Bar-On Emotional Quotient Inventory, Youth Version (EQ-i:YV) with brain activity during perception of fearful faces in 16 healthy children and adolescents. Consistent with the neural efficiency hypothesis, higher EQ correlated negatively with activity in the somatic marker circuitry and other paralimbic regions. Positive correlations were observed between EQ and activity in the cerebellum and visual association cortex. The findings suggest that the construct of self-reported EQ in adolescents is inversely related to the efficiency of neural processing within the somatic marker circuitry during emotional provocation.
\end{abstract}

The transition from childhood to adulthood involves dramatic changes in physical, cognitive, social, and emotional functioning (Spear, 2000). During this adolescent period, developing children begin to focus more heavily on their social relationships, strengthening bonds with peers while slowly weaning themselves from the emotional support of their parents (Kloep, 1999; Nelson, Leibenluft, McClure, \& Pine, 2005). With the emergence of adolescence, the developing child is confronted with many new challenges that require a different set of skills and abilities, particularly in the emotional and social realms. In order to manage their interpersonal relationships effectively, each adolescent must develop a well-tuned set of emotional and social capacities: (1) self-awareness and the ability to communicate emotional needs effectively, (2) accurate perception of the emotions of others and the ability to respond appropriately to those emotions, (3) the ability to regulate emotions in a healthy and productive way, (4) flexible coping skills and effective interpersonal problem solving, and (5) a positive affective outlook when faced with adversity (Bar-On, Tranel, Denburg, \& Bechara, 2003). Persons who possess and effectively utilize these emotional and social capacities have been described as showing emotional intelligence (EQ; Bar-On \& Parker, 2000; Mayer, DiPaolo, \& Salovey, 1990). In recent years, the concept of EQ has gained considerable interest in the popular media, as well as in academic circles (Goleman, 1995; Mayer, Caruso, \& Salovey, 1999). Although a number of definitions of EQ have emerged, one definition suggests that it is "an array of noncognitive capabilities, competencies, and skills that influence one's ability to succeed in coping with environmental demands and pres- sures" (Bar-On, 1997, p. 14). Several authors have made a strong case for considering EQ to be a standard form of intelligence (Mayer et al., 1999; Mayer, Salovey, Caruso, \& Sitarenios, 2001), although qualitatively different from traditional "cognitive" types of intelligence (Bar-On et al., 2003).

An understanding of the neurobiological substrate of EQ in adults is beginning to emerge (Bar-On et al., 2003). One influential theory that is particularly relevant to the neurobiology of emotional intelligence is the somatic marker hypothesis (Damasio, 1994). According to this hypothesis, decision making is influenced by previously learned associations between emotionally evocative events and the affective response that occurred as a result. These affective responses are essentially somatic states (or mental simulations thereof) that are reactivated when one encounters a biologically relevant situation that is similar to one encountered previously. The activation of these somatic markers produces an emotional bias that aids in decision making when circumstances are uncertain or when there are too many alternatives to compare. In such situations, somatic markers contribute to decision making by biasing choice selections away from alternatives that evoke negative somatic states and toward choices that evoke positive somatic states. Within this framework, an emotionally intelligent individual may be understood as one who is effective at utilizing these somatic-emotional signals to appropriately and advantageously guide decision making and social behavior.

Evidence from neuropsychological studies of patients with brain damage and from functional neuroimaging studies of healthy individuals suggests that there are sev- 
eral brain regions that are critical to the process of using somatic markers to guide decision making toward advantageous outcomes. The most prominent include the amygdala, insular cortex, and ventromedial prefrontal cortex (Bar-On et al., 2003), although many others, such as the cerebellum and ventral striatum, are likely to be involved as well, due to their role in affective processing (Christakou, Robbins, \& Everitt, 2004; Exner, Weniger, \& Irle, 2004; Lee et al., 2004; Levy \& Dubois, 2006; ShamayTsoory et al., 2005). The amygdala is known to be critical for the ability to perceive some classes of emotionally arousing stimuli and for forming associations between aversive stimuli and an appropriate negative emotional response, such as fear (Buchel, Morris, Dolan, \& Friston, 1998; Furmark, Fischer, Wik, Larsson, \& Fredrikson, 1997). The insula, on the other hand, appears to be important for monitoring ongoing somatic and visceral states (Dunckley et al., 2005; Reiman, 1997; Reiman et al., 1997). The ventromedial prefrontal cortex has been shown to be particularly important for the ability to use somatic markers to influence decision making toward advantageous outcomes (Bechara, Damasio, \& Damasio, 2000; Bechara, Damasio, Damasio, \& Lee, 1999; Bechara, Tranel, \& Damasio, 2000). Damage to this somatic marker circuitry has been shown to lead to deficits in judgment and decision making, social functioning, and EQ (Bar-On et al., 2003). Although a large literature is emerging with regard to EQ in adults, the developmental basis of these capacities during childhood and adolescence has been virtually unexplored. The accelerated emotional and social development that is typical of adolescence suggests that this transitional period may be particularly important for the emergence of emotionally intelligent behavior.

Although it is clear that there are individual differences in the emotional and social skills that are important to managing interpersonal relationships and coping successfully with environmental demands and pressures, the specific manner in which the somatic marker circuitry is involved in these capacities is currently unknown. Many studies of learning and development suggest that neural activity becomes more efficient and focused as individuals acquire greater skills and experience, a phenomenon that constitutes the basis of the neural efficiency hypothesis. For instance, Olson and colleagues (Olson et al., 2006) found that as performance on a sequence-learning task improved, there were corresponding decreases in cerebral blood flow within regions of the brain important for task completion, suggesting that the brain required less activity (i.e., developed greater neural efficiency) to perform the task at the same level of accuracy. Similarly, individuals who show the greatest improvement on a learned task also show the greatest reductions in regional cerebral glucose metabolism during subsequent performance of the task, suggesting increased neural efficiency (Haier, Siegel, et al., 1992). Highly trained concert pianists show significantly lower cerebral activity during bimanual sequential finger movements that mimic piano playing, as compared with nonmusicians, suggesting that the expert pianists possess greater efficiency of neural processing when engaged in the same task (Haslinger et al., 2004). Further- more, traditional measures of cognitive intelligence have been shown to correlate negatively with rates of cerebral glucose metabolism following learning, presumably reflecting greater neural efficiency in more intelligent individuals (Haier, Siegel, Tang, Abel, \& Buchsbaum, 1992). A similar general phenomenon appears to emerge as children develop through adolescence and into adulthood. As adolescents mature, prefrontal activity becomes progressively more focal and specialized, suggesting greater neural efficiency with development (Brown et al., 2005; Durston et al., 2006; Tamm, Menon, \& Reiss, 2002). At present, it is not known whether the development of the emotional and social skills making up EQ is associated with a similar change in neural efficiency.

To better understand the neurobiology of EQ during adolescent development, we used functional magnetic resonance imaging (fMRI) to study whole-brain activity during a fearful-face perception task known to activate regions of the brain involved in emotional processing in adolescents and adults (Baird et al., 1999; Killgore \& Yurgelun-Todd, 2001). Brain activity during this task was correlated in a voxelwise manner with scores on a wellvalidated and standardized measure of EQ for children and adolescents (Bar-On \& Parker, 2000). On the basis of the neural efficiency hypothesis, we predicted that higher EQ scores in adolescents would be negatively correlated with neural activity within the somatic marker circuitry, including the ventromedial prefrontal cortex, amygdala, and insula, during fear perception. We also performed whole-brain exploratory analysis to determine whether there were other, nonhypothesized regions that might also be associated with EQ in adolescents.

\section{METHOD}

\section{Subjects}

Sixteen healthy right-handed children ( 9 of them male, 7 female) participated in the present study by completing an EQ scale and undergoing fMRI. The ages of these children ranged from 8 to 15 years $(M=11.6, S D=2.1)$, in order to capture the period most consistent with the emergence of adolescent developmental changes. Fifteen of the subjects were right-handed, according to self-report. Although we have previously reported data from this sample as it relates to different behavioral measures (Killgore \& Yurgelun-Todd, 2005, 2006), the present $E Q$ findings are novel and have not been reported elsewhere. The children were free of any history of psychiatric or neurologic illnesses, on the basis of a structured clinical interview by a trained psychometric technician, using the Kiddie-Schedule for Affective Disorders and Schizophrenia (K-SADS). All the subjects had normal visual acuity (or corrected to normal with contact lenses). The subjects were recruited by advertisements in newspapers within the local community of Belmont, MA. The procedures and potential risks of the study were explained to all of the children and their parents, and written informed consent was obtained prior to participation. Each subject received a small financial compensation for his or her time.

\section{Emotional Intelligence Scale}

Several hours prior to the fMRI session, the adolescent children were administered the Bar-On Emotional Quotient Inventory, Youth Version (EQ-i:YV; Bar-On \& Parker, 2000). The EQ-i:YV is an easily administered self-report inventory that yields scores on five primary dimensions derived from the Bar-On model of EQ and a global total score of EQ (Bar-On \& Parker, 2000). These scales and 
subscales include intrapersonal, interpersonal, adaptability, stress management, and general mood, as well as a total EQ score. According to the test manual, the intrapersonal scale measures the child's awareness of his or her own feelings and the ability to understand, express, and communicate effectively about his or her feelings and needs. On the other hand, the interpersonal scale measures the capacities of the child to engage in satisfying social and interpersonal relationships, including empathy, social responsibility, and other social-emotional skills that serve to maintain human relationships. The adaptability scale measures the ability of the child to respond flexibly to changing circumstances and situations by engaging in effective problem solving, emotional adaptation, and effective emotional reality testing. The inventory also includes a stress management scale, which measures the child's ability to withstand difficult and stressful situations by using positive coping skills and the ability to control emotions and impulsive behaviors. The EQ-i:YV also includes a scale that measures general mood, a construct that includes the tendency to maintain a positive and optimistic perspective, to enjoy oneself and others, and to generally maintain a happy and satisfied approach to life. Finally, the inventory provides an overall assessment of EQ, the total EQ score. Total EQ is a global indication of a child's emotional and social intelligence abilities based on the domains discussed previously. According to the manual, high scorers on total EQ are typically happy and highly effective at proactively engaging most of life's emotional and social demands (Bar-On \& Parker, 2000). The EQ-i:YV consists of 60 self-report questions (e.g., "I usually know how other people are feeling"), each of which is answered on a 4-point Likert-type scale with the following response options: very seldom true of me, seldom true of me, often true of me, and very often true of me. For the present study, raw scores on each of the six scales were transformed into age-scaled $T$ scores according to the published normative data provided in the test manual. The EQ-i:YV was completed on the same day that the children completed the functional neuroimaging scans.

The EQ-i:YV was normed on a North American sample of 9,172 children and adolescents ranging in age from 7 to 18 years, with a mean age nearly identical to that of the present sample for males $(M=11.6$ years $)$ and females $(M=11.7$ years; Bar-On \& Parker, 2000). According to the normative data presented in the test manual, the internal consistency of the scales ranges from a low of .65 (interpersonal scale) to a high of .90 (total EQ, stress management, and general mood), with an average Cronbach's coefficient of $\alpha=.84$, suggesting good-to-high internal consistency reliability (Bar-On \& Parker, 2000). Three-week test-retest reliability estimates are also provided for a sample of 60 children. These coefficients ranged from .77 (general mood) to .89 (total EQ). The Bar-On model of EQ has been validated in a number of studies for both the adolescent and the adult scales, and these two scales are moderately to highly correlated in older adolescents. In adults, the EQ-i has shown good convergent and discriminant validity, assessing a broad range of emotional and personality constructs (Bar-On, 1997; Dawda \& Hart, 2000). For the adolescent version, the test manual reports that the factorial structure of the inventory in a sample of 9,172 children closely matched major EQ scales (Bar-On \& Parker, 2000). Construct validity was supported by the expected pattern of convergent and discriminant correlations with scales of the NEO-Five Factor Inventory (Costa \& McCrae, 1992) in a sample of 102 adolescents, as well as with several scales of internalizing and externalizing problem behavior (Bar-On \& Parker, 2000). A recent study also demonstrated that the EQ-i:YV was significantly predictive of parent-reported child behavior problems and other emotional difficulties (Shuler, 2005).

\section{fMRI Stimulation Paradigms}

After completion of the EQ-i:YV, the children underwent a series of fMRI scans. During functional scanning, the adolescents viewed a series of six photographs of faces expressing the emotion of fear (Ekman \& Friesen, 1976). The face stimuli were back-projected via a magnetically shielded LCD video projector onto a translucent screen placed at the foot of the scanning table. The stimuli were easily viewed from a mirror mounted to the head coil. The stimuli were presented during five alternating 30 -sec stimulus/rest periods, yielding a 150 -sec scanning session. During the baseline and rest intervals, a small white circle appeared in the center of the screen, and the children were told simply to maintain their gaze on the circle. During each 30 -sec stimulation period, three different photographs of faces expressing fear were displayed sequentially for $9.5 \mathrm{sec}$ each, separated by a $0.5-\mathrm{sec}$ interstimulus interval. In order to ensure that the children attended to the stimuli, they were informed that they would be quizzed after the end of each scan regarding the types of emotions they had seen.

\section{Neuroimaging Methods}

At the outset of each functional scan, three dummy images were taken to reduce nonsteady-state effects, followed by acquisition of 50 echoplanar images over $150 \mathrm{sec}$. Functional images were acquired using a 1.5 Tesla GE LX MRI scanner equipped with a quadrature $\mathrm{RF}$ head coil $\left(\mathrm{TR}=3 \mathrm{sec}, \mathrm{TE}=40 \mathrm{msec}\right.$, flip angle $\left.=90^{\circ}\right)$. Head motion was minimized by placing secure but comfortable foam padding around the head. A tape strap across the forehead was also applied as a tactile reminder to the child to remain still. Functional images were acquired over 20 coronal slices ( $7 \mathrm{~mm}$; 1 -mm gap), with a 20 -cm field of view and a $64 \times 64$ acquisition matrix. This provided an in-plane resolution of $3.125 \times 7 \times 3.125 \mathrm{~mm}$. We also obtained matched T1-weighted high-resolution images for every child at the beginning of each scanning session.

\section{Image Processing}

Functional imaging data were preprocessed and statistically analyzed in SPM99 (Friston et al., 1995). Initially, the functional images were corrected for motion in three dimensions, using an intrarun realignment algorithm in SPM99. The data were then convolved into three-dimensional Montreal Neurological Institute (MNI) space, spatially smoothed using a nonisotropic Gaussian kernel (full-width half-maximum $=10 \mathrm{~mm}$ ), and were resliced to $2 \times 2 \times 2 \mathrm{~mm}$, using sinc interpolation.

\section{Statistical Analysis}

In order to permit inference to the population from which the data were collected, a two-step random-effects approach was utilized (Penny, Holmes, \& Friston, 2003). This process involved conducting a fixed-effects analysis whereby the activation for the fearful-face expression condition was contrasted with that of the fixation control for each subject. The procedure yielded a contrast image for each subject, representing the difference between the fearful-face stimulus and the control condition. A random-effects multiple regression analysis was then conducted on these contrast images (Penny et al., 2003). Specifically, contrast images were entered into a series of multiple linear regression models in SPM99, with the total EQ variable entered as the covariate of interest and the age and gender of the subjects entered as nuisance variables. The height threshold was set at $p<.001$, and the $k$ threshold (extent) set at 10 contiguous voxels. This yielded an activation map representing the regions that were significantly correlated with total EQ scores. In order to examine the relationship between regional brain activity and scores on the primary subtests of the EQ-i:YV, five additional regression analyses were undertaken in the same manner as that described above for each subscale of the inventory. For visualization, the resulting SPM $\{\mathrm{t}\}$ maps were overlaid on an average template brain within the standardized coordinate space of the MNI.

\section{Hypothesized Regions-of-Interest Analysis}

We were also interested in the relationship between general emotional intelligence and activity within specific brain regions that are known to be involved in the integration of cognitive and affective processing. Thus, we created region-of-interest (ROI) masks for three pairs of brain regions/structures that have been hypothesized to be part of a neural system involved in emotional and social intelligence (Bar-On et al., 2003), including the ventromedial prefrontal 
Table 1

Scaled Scores for the Adolescents on the Six Bar-On EQ-i:YV Scales

\begin{tabular}{lrrl}
\hline Bar-On EQ-i:YV Scale & \multicolumn{1}{c}{$M$} & \multicolumn{1}{c}{$S D$} & Range \\
\hline Total EQ & 102.19 & 13.93 & $79-130$ \\
Intrapersonal & 96.94 & 14.32 & $67-119$ \\
Interpersonal & 94.88 & 12.31 & $78-121$ \\
Adaptability & 102.44 & 14.48 & $80-127$ \\
Stress management & 102.31 & 10.51 & $79-116$ \\
General mood & 96.37 & 8.60 & $88-117$ \\
\hline
\end{tabular}

Note $-N=16$.

cortex (i.e., the superior orbital frontal gyrus, gyrus rectus, medial orbital frontal gyrus, and anterior cingulate gyrus), the amygdala, and insular regions. ROI masks were created using the Wake Forest University Pickatlas utility (Maldjian, Laurienti, Kraft, \& Burdette, 2003), with region boundaries for these three regions defined by the published anatomical atlas of Tzourio-Mazoyer and colleagues (Tzourio-Mazoyer et al., 2002). Masks were applied to the data, and threshold levels were reduced to reveal all voxels. Within each ROI, the voxel with the maximal correlation with total EQ was identified, and the adjusted fMRI data were extracted and plotted.

\section{RESULTS}

\section{Emotional Intelligence Scores}

Table 1 shows the mean age-scaled score values for the Bar-On EQ-i:YV. The mean scores for all six scales did not differ significantly from the population mean of 100 (all $p \mathrm{~s}>.05$ ), suggesting that our sample was within the normal range on these indices of EQ. Age did not appear to significantly affect EQ in this sample of children, since none of the EQ scales or subscales were correlated with age, regardless of whether raw or age-scaled scores were examined (all $p \mathrm{~s}>.05$ ).

\section{Neural Correlates of Total EQ}

As is evident in Figure 1 and Table 2, higher scores on total EQ were associated with significantly increased blood oxygen level dependent (BOLD) activity in only two discrete brain regions, including the right superior and middle occipital gyrus (Brodmann's area [BA] 19) and the left cerebellum. In contrast, total EQ was negatively correlated with widespread BOLD activity, primarily encompassing limbic and paralimbic structures, such as the insula, hippocampus, parahippocampal gyrus, and middle cingulate gyrus (see Table 2). Overall, these data suggest that those children with the highest EQ scores tended to have less activity in these limbic and paralimbic regions when presented with photographs of fearful faces.

\section{Activation Correlates of EQ Subscales}

Scores on the five subscales of the EQ-i were also examined in relation to BOLD activation during fear perception. Regions showing significant correlations on each of the subscales are presented in Table 2, along with coordinates for local maxima, and are shown graphically in Figure 2. For the intrapersonal scale, positive correlations were observed almost exclusively in posterior brain regions involved in primary and secondary visual processing, such as the precuneus, cuneus, middle occipital gyrus, and superior parietal gyrus. Higher scores on the intrapersonal scale were also associated with reduced activity in the left sensory motor cortex and right middle
A
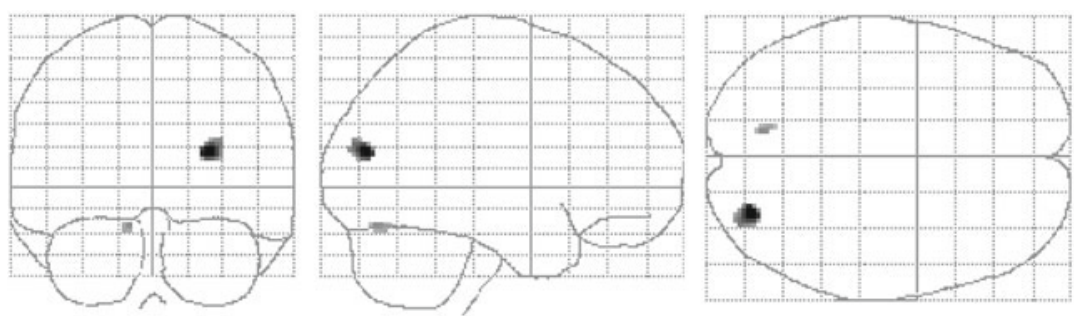

B
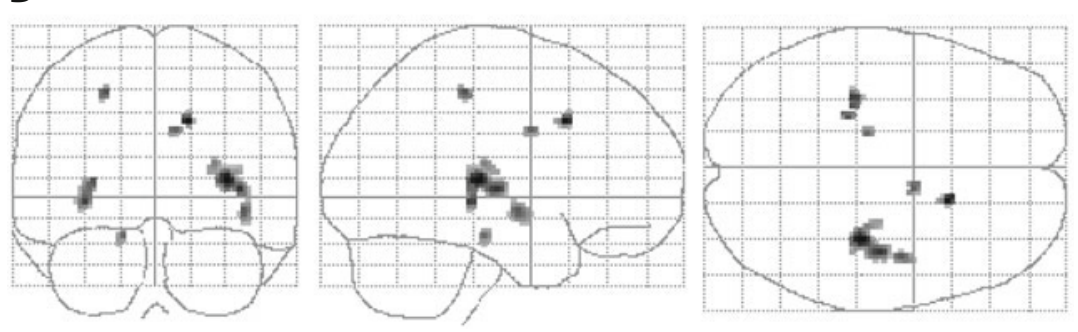
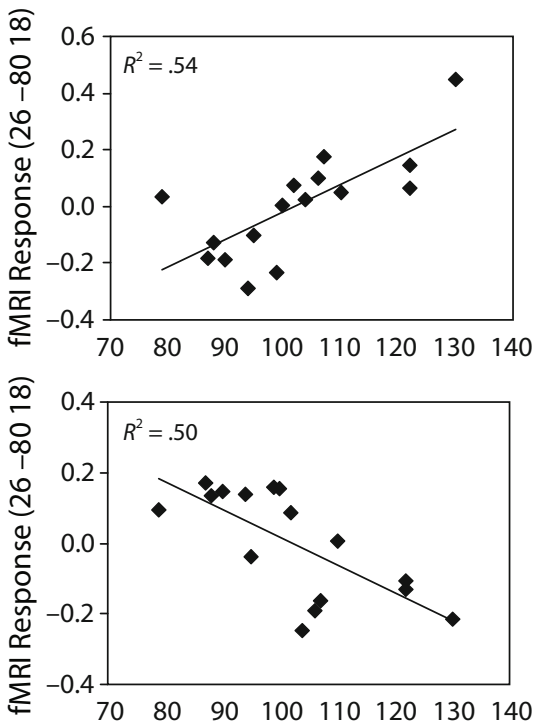

Figure 1. Two regions showed significant positive correlation of BOLD signal change with total emotional intelligence (EQ) scores on the Bar-On EQ-i:YV during a fearful-face perception task (after covariation for age and gender). The figures on the left show "glass brain" representations of the anatomical locations of the maximally correlated voxels $(p<.001)$, and the figures on the right show the scatterplots representing the relationship between EQ and the adjusted fMRI response at the cluster maxima. (A) Higher total EQ scores were associated with significantly greater signal change within the left cerebellum and right middle occipital gyrus. (B) Total EQ was negatively correlated with signal change in a number of limbic and paralimbic regions, including the insula, middle cingulate gyrus, hippocampus, and parahippocampal gyrus. 
Table 2

Regional Correlations Between Bar-On EQ-i:YV Scores and BOLD Signal Intensity in Adolescent Children Viewing Images of Fearful Faces

\begin{tabular}{lrrrrr}
\hline Bar-On EQ-i:YV Scale & Volume & $x$ & $y$ & $z$ & $z$ Score \\
\hline Total EQ & & & & & \\
$\quad$ Positive correlations & & & & & \\
$\quad$ R. superior occipital gyrus & 73 & 26 & -80 & 18 & 3.98 \\
$\quad$ L. cerebellum (area 6) & 11 & -12 & -74 & -18 & 3.33 \\
Negative correlations & & & & & \\
R. insula* & 159 & 34 & -26 & 8 & 3.74 \\
R. middle cingulate gyrus & 15 & 16 & 16 & 36 & 3.71 \\
L. hippocampus* & 48 & -34 & -30 & -2 & 3.54 \\
L. postcentral gyrus* & 13 & -24 & -32 & 50 & 3.47 \\
R. insula & 33 & 42 & -6 & -6 & 3.45 \\
R. middle cingulate gyrus* & 10 & 10 & 0 & 32 & 3.42 \\
L. parahippocampal gyrus & 14 & -16 & -22 & -18 & 3.40
\end{tabular}

Intrapersonal

Positive correlations

$\begin{array}{lrrrrr}\text { R. precuneus } & 54 & 20 & -58 & 14 & 3.85 \\ \text { L. superior parietal gyrus } & 58 & -18 & -74 & 54 & 3.76 \\ \text { R. cuneus } & 16 & 20 & -74 & 26 & 3.61 \\ \text { L. middle occipital gyrus } & 26 & -42 & -76 & 8 & 3.45 \\ \text { R. middle occipital gyrus } & 17 & 30 & -68 & 36 & 3.37 \\ \text { Negative correlations } & & & & & \\ \text { L. postcentral gyrus } & 54 & -52 & -16 & 28 & 3.77 \\ \text { R. middle temporal gyrus } & 10 & 54 & 4 & -28 & 3.70 \\ \text { L. precentral gyrus } & 10 & -46 & 4 & 20 & 3.38\end{array}$

Interpersonal

Positive correlations

L. cerebellum (area 6)

R. middle temporal gyrus

R. middle occipital gyrus

R. middle occipital gyrus*

Negative correlations

$\mathrm{R}$. anterior cingulate gyrus

$\mathrm{R}$. anterior cingulate gyrus

L. anterior cingulate gyrus

$\begin{array}{rrrrr}29 & -30 & -56 & -30 & 4.09 \\ 84 & 50 & -66 & 4 & 3.94 \\ 98 & 30 & -80 & 24 & 3.85 \\ 22 & 36 & -74 & 6 & 3.52 \\ & & & & \\ 223 & 8 & 42 & 12 & 4.25 \\ 50 & 4 & 44 & 0 & 3.53 \\ 14 & -8 & 42 & 0 & 3.33\end{array}$

Adaptability

Positive correlations

Negative correlations

L. precentral gyrus**

L. fusiform gyrus

R. insula

R. fusiform gyrus

Stress management

Positive correlations

$\begin{array}{llllll}\text { R. middle occipital gyrus } & 64 & 32 & -82 & 20 & 3.56\end{array}$

$\begin{array}{llllll}\text { R. superior occipital gyrus } & 14 & 24 & -70 & 30 & 3.44\end{array}$

Negative correlations

R. postcentral gyrus

R. postcentral gyrus*

R. insula

L. parahippocampal gyrus

$\begin{array}{lllll}20 & 24 & -34 & 62 & 3.67\end{array}$

$\begin{array}{lllll}11 & 32 & -24 & 40 & 3.47\end{array}$

$\begin{array}{lllll}60 & 40 & -16 & 4 & 3.45\end{array}$

$\begin{array}{lllll}47 & -16 & -26 & -18 & 3.44\end{array}$

General mood

Positive correlations

Negative correlations temporal gyrus. Higher scores on the interpersonal scale were associated with greater activity in the left cerebellum and right temporal and occipital regions, whereas activity in the anterior cingulate gyrus was negatively correlated with this scale. Scores on the adaptability scale did not correlate positively with brain activity in any region, although significant negative correlations were present in the fusiform gyrus and insula and in the white matter between the precentral gyrus and the caudate nucleus. Adolescents with higher stress management scale scores showed higher activity in the right occipital regions during fearful-face conditions but showed decreased activity in the primary sensory cortex, insula, and parahippocampal gyrus. Finally, scores on the general mood scale were uncorrelated with BOLD responses during the fearful-face task.

\section{ROI Analysis}

Three regions (i.e., the ventromedial prefrontal cortex, amygdala, and insula) were hypothesized a priori to show significant correlations with total EQ scores. Figure 3 shows representative coronal slices of each structure of interest and scatterplots for the maximally activated voxel in each lateralized ROI, regardless of direction. As was hypothesized, BOLD activity in all three of these affectprocessing regions, after covariation for age and sex, was negatively correlated with total EQ scores (two-tailed). Specifically, total EQ was negatively correlated with activity within the ventromedial prefrontal cortex (left $r=$ $-.56, p=.025$; right $r=-.61, p=.013$ ) and amygdala (left $r=-.36, p=.17$; right $r=-.55, p=.027$ ) and, most prominently, with activity within the insular cortices (left $r=-.64, p=.007$; right $r=-.70, p=.002$ ). These data suggest that children with lower EQ scores tended to show greater activation of these three key somatic marker regions when processing facial expressions of fear than did their peers with higher EQ scores.

\section{DISCUSSION}

In this sample of young adolescents, EQ scores were significantly related to changes in BOLD fMRI activity within several emotionally relevant regions of the brain in response to the presentation of fearful faces. Overall, with higher scores on total EQ, BOLD activity was greater in the left cerebellum and visual association regions of the right occipital cortex. Most notably, however, total EQ scores were negatively correlated with BOLD activity across several predominantly limbic and paralimbic regions of the brain, including the insula, hippocampus, and middle cingulate and parahippocampal gyri. These findings suggest that adolescents with relatively poorly developed EQ skills responded to emotionally provocative stimuli with greater and more extensive brain activation in these regions than do their peers with more well developed EQ capacities. Moreover, this pattern was particularly prominent within brain regions hypothesized to be critical for the perception of somatic state information and the ability to use that information to guide decision making
Note-L, left hemisphere; R, right hemisphere. Atlas coordinates are listed in the standard space of the Montreal Neurological Institute. All regions reported are significant at $p<.005$, uncorrected; $k$ threshold (extent $)=10 . \quad{ }^{*}$ The voxel with the highest correlation fell within unlabeled white matter, but within $6 \mathrm{~mm}$ of a labeled region. ${ }^{* *}$ The voxel with the highest correlation fell within unlabeled white matter, but between 6 and $12 \mathrm{~mm}$ of a labeled region. The nearest labeled region is listed. 

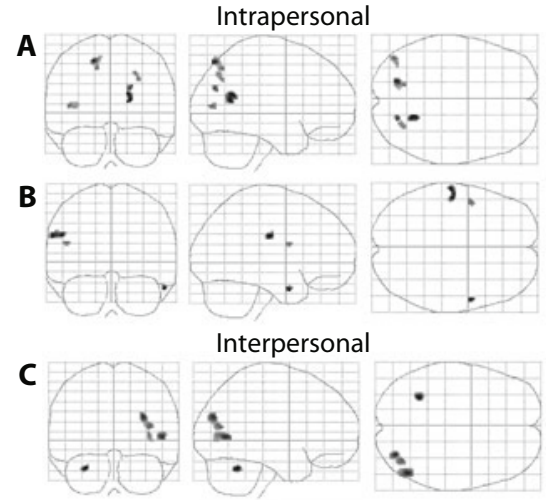

D
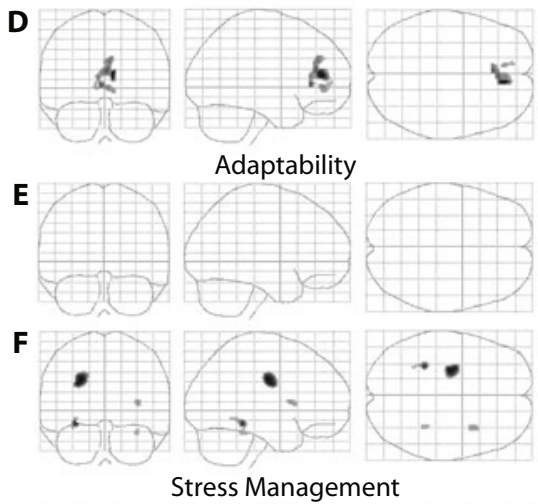

$\mathbf{G}$

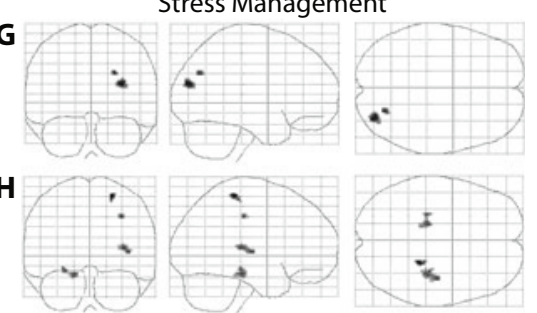

General Mood

I

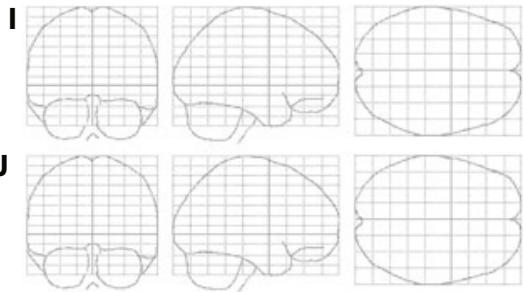

Figure 2. Subscale scores of the Bar-On EQ-i:YV were significantly related to BOLD signal change during the fearful-face perception task. For each of the five subscales, "glass brain" representations show the location of regions where the BOLD signal was either positively or negatively correlated with the subscale score. Scores on the intrapersonal scale correlated positively with activity in the precuneus and visual association cortex (A) and negatively with the primary sensory-motor cortex and the middle temporal gyrus (B). Scores on the interpersonal scale showed positive correlations in the left cerebellum and visual association cortices $(C)$ and negative correlations within the anterior cingulate gyrus and medial prefrontal cortex (D). Scores on the adaptability scale showed no positive correlations ( $E$ ) but were negatively correlated with activity in the fusiform gyrus and insula $(F)$. The stress management scale was positively correlated with activity in the visual association cortex (G) and negatively correlated with activity in the insula and primary somatosensory cortex $(H)$. The general mood scale was not positively (I) or negatively $(\mathrm{J})$ correlated with activity in any brain region.
(Bar-On et al., 2003; Damasio, 1994, 1996). On the basis of previous functional neuroimaging research suggesting that individuals with more well developed skills and abilities tend to show greater neural efficiency in the form of reduced functional activation during relevant tasks (Haier, Siegel, MacLachlan, et al., 1992; Haier, Siegel, Tang, Abel, \& Buchsbaum, 1992; Haslinger et al., 2004; Olson et al., 2006), we hypothesized that EQ would correlate negatively with activity within three regions previously identified as important for the formation of somatic markers (i.e., bioregulatory somatic states that bias response selection and decision making), including the ventromedial prefrontal cortex, amygdala, and insula. Indeed, focused analyses within each of these predefined regions revealed that EQ was negatively correlated with activity within each of the major nodes of the somatic marker circuitry during the fear perception task. These findings are consistent with data for patients with lesions to this same neural circuitry (Bar-On et al., 2003), supporting the extension of the neural efficiency hypothesis to the concept of emotional intelligence.

The finding of an inverse relationship between activity in the major neuroanatomic regions of the somatic marker circuitry and total EQ is particularly interesting and suggests that adolescents with the greatest degree of EQ tended to have the least reactivity within these regions in response to emotionally provocative stimuli. For instance, the fearful-facial expression stimuli used in the present study have previously yielded increased activation within the amygdala in both adolescents and adults (Baird et al., 1999; Killgore, Oki, \& Yurgelun-Todd, 2001; Killgore \& Yurgelun-Todd, 2001). The present data suggest, however, that the degree of reactivity of the amygdala to these threat-related emotional expressions is negatively related to global EQ, with less amygdala reactivity seen in those adolescents with higher EQ scores. This finding is consistent with other neuroimaging data that suggest that reduced BOLD responses are associated with enhanced neural efficiency (Rissman, Eliassen, \& Blumstein, 2003) and with greater skill at completing cognitive and motor tasks (Tomasi, Ernst, Caparelli, \& Chang, 2004). For instance, as individuals learn new motor or cognitive skills and become proficient in implementing those skills, their behavioral performance typically remains stable or even improves, whereas the brain activity associated with those skills is concomitantly reduced (Bergerbest, Ghahremani, \& Gabrieli, 2004; Poldrack, Desmond, Glover, \& Gabrieli, 1998; Tomasi et al., 2004). These findings suggest, therefore, that adolescents with well-developed EQ capacities may possess a more efficient and effectively functioning somatic marker circuitry, leading to greater expertise in reading emotional stimuli, but requiring less activation within the neural structures involved in emotional processing and the formation of somatic markers.

The inverse relationship between total EQ and signal change in the somatic marker circuitry is also consistent with previous findings demonstrating greater resting activity and neural responsiveness in these same regions during negative mood states and in the presence of mood 
A

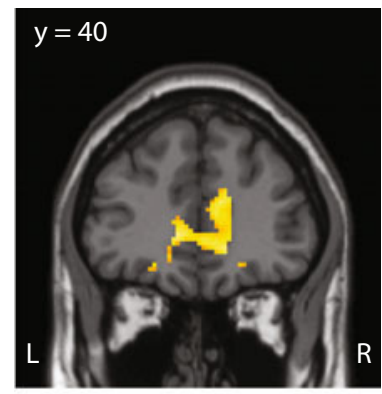

B

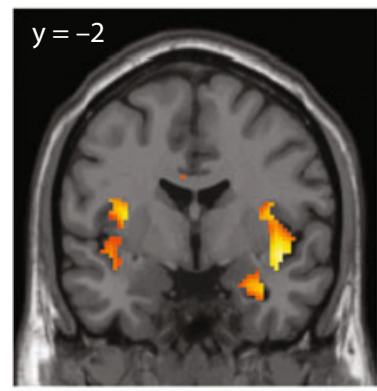

C

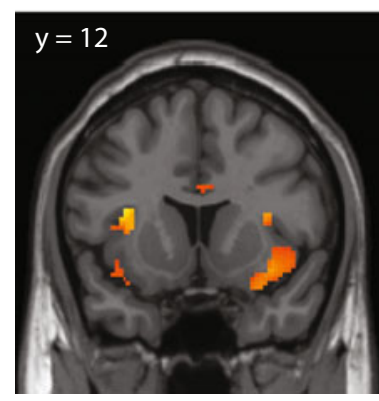

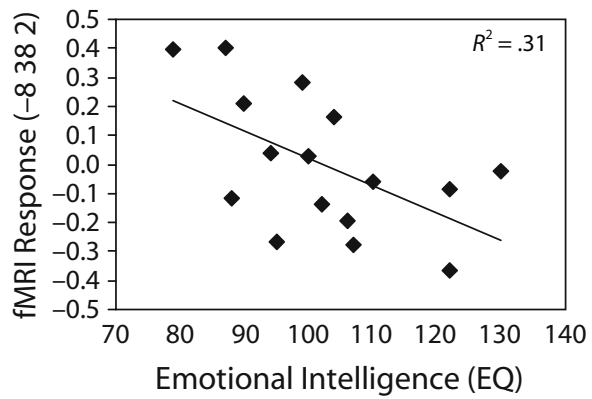
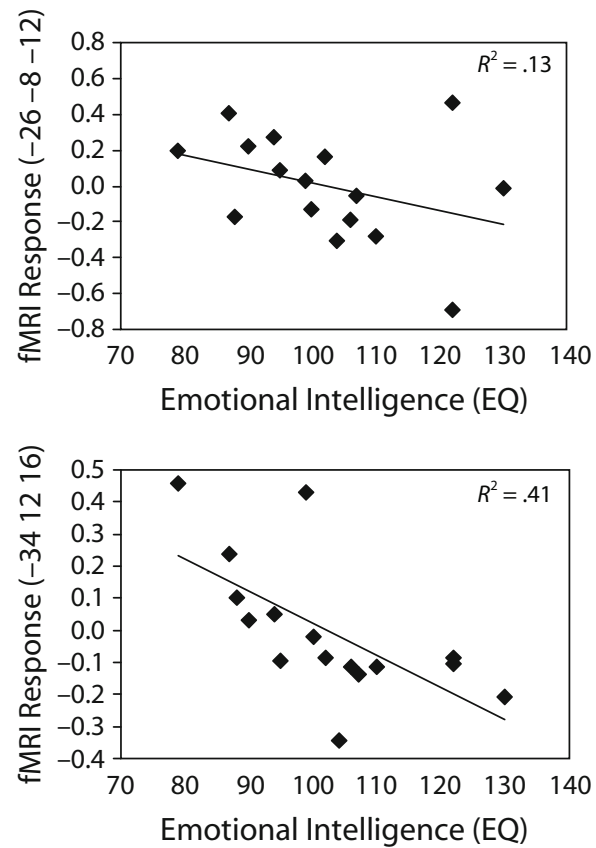
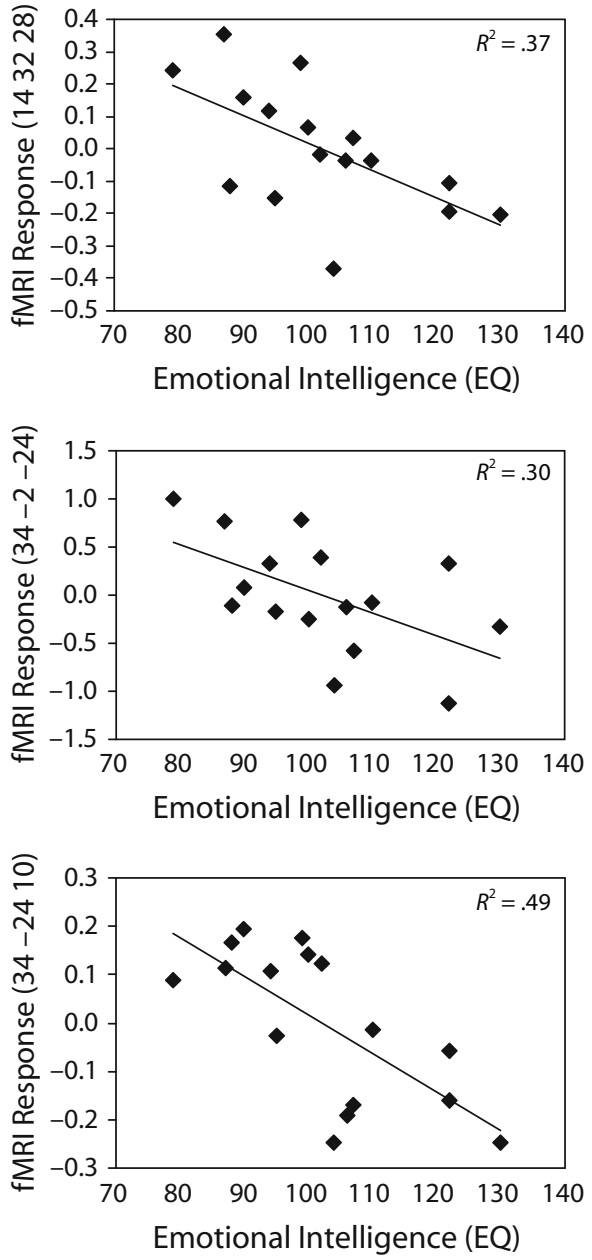

Figure 3. During the fearful-face perception task, negative correlations were evident between total emotional intelligence (EQ) scores and BOLD signal change within the three major brain structures that make up the somatic marker circuitry, including the ventromedial prefrontal cortex, amygdala, and insula. These three regions have been suggested to be critical nodes in the circuitry of EQ (Bar-On, Tranel, Denburg, \& Bechara, 2003; Damasio, 1994). The panels on the left side show representative coronal slices that provide visualization of activity within the major structures making up the somatic marker circuitry. For visualization, activity is displayed at a liberal threshold (height, $p<.05, k=10$ ). The panels on the right show the scatterplots representing the negative relationship between EQ and the adjusted $f$ MRI response at the cluster maxima for the left- and right-hemisphere regions of interest. (A) Adolescents with higher total EQ scores demonstrated less activity bilaterally within the medial prefrontal cortex in response to fearful expressions. Similarly, activity in the right amygdala (B) and bilateral insular cortices (C) were lower in adolescents with higher total EQ scores when fearful emotions were viewed.

and anxiety disorders. Several studies suggest that negative mood states and depressive illness are associated with increased activity within the amygdala (Abercrombie et al., 1998; Anand et al., 2005; Drevets, 1999; Ray et al., 2005). Furthermore, activity within the amygdala correlates with the experience of anxiety (Killgore \& YurgelunTodd, 2005; Lorberbaum et al., 2004; Paulus, Feinstein, Castillo, Simmons, \& Stein, 2005), and the amygdala has been shown to be hyperactivated in patients with a variety of anxiety and mood disorders (Fredrikson \& Furmark, 2003; Sakai et al., 2005), including phobias, posttraumatic stress disorder, and bipolar mood disorder (Rauch et al., 2000; Straube, Mentzel, \& Miltner, 2006; YurgelunTodd et al., 2000). Similarly, greater activity within ventral regions of the prefrontal cortex is commonly seen in functional neuroimaging studies of negative affect and de- pression (Keedwell, Andrew, Williams, Brammer, \& Phillips, 2005; Mayberg, 1997; Mayberg et al., 1999). Finally, although some evidence has associated insular activation with internally generated positive affect (Teasdale et al., 1999) and with euphoria during cocaine administration (Breiter et al., 1997), activity within the insular cortex is most often associated with the experience of negative or unpleasant emotions or interoceptive discomfort (Dunckley et al., 2005; Reiman, 1997; Reiman et al., 1997), during the perception of stimuli that suggest or directly evoke disgust (Phillips et al., 1997; P. Wright, He, Shapira, Goodman, \& Liu, 2004), and such activity correlates with the intensity of experienced emotion (Aron et al., 2005). These studies suggest that greater basal activity and/or responsiveness within the somatic marker circuitry is often correlated with the intensity of affective experience. In- 
terestingly, in the present study, greater responsiveness within these same regions was generally associated with lower measured EQ.

In contrast to the large number of negative correlations between total EQ and various limbic and paralimbic regions, we observed positive correlations only between total EQ scores and two discrete cerebral regions, including the right occipital cortex (BA 19) and the left cerebellum. Gray matter volume within the occipital cortex is related to general cognitive intelligence (Haier, Jung, Yeo, Head, \& Alkire, 2004), and this region is known to be an important visual association region of the brain, involved in simple feature analysis (Boucart et al., 2000), generation of mental imagery (D'Esposito et al., 1997), mental image transformation (Boucart et al., 2000), and biological motion (Vaina, Solomon, Chowdhury, Sinha, \& Belliveau, 2001), as well as the processing of faces and other complex visual stimuli (Blonder et al., 2004). The present findings suggest that adolescents with higher EQ show greater activation of this visual association region during the processing of facial cues of fear. When presented with a complex emotional facial expression, adolescents with more well developed EQ appear to draw more heavily upon higher order visual associative processing regions, perhaps in an attempt to fully extrapolate affective meaning from the face. The second area showing a positive correlation with EQ was a small region in the left cerebellum, a structure that has long been associated with fine motor control, coordination, and complex motor sequencing (Ghez \& Fahn, 1985). Recent research now suggests, however, that the cerebellum may play a much greater role than has previously been thought in complex cognitive processes, including the modulation of thought and emotion (Schmahmann, 1991, 2004; Schmahmann \& Sherman, 1998). Anatomic studies have shown that there are indirect connections between the cerebellum and heteromodal association cortices of the prefrontal and parietal lobes (Asanuma, Thach, \& Jones, 1983; Middleton \& Strick, 1994), and patients with cerebellar damage often show a number of deficits in executive function, personality, and affective regulation that are generally ascribed to the prefrontal cortex (Riva \& Giorgi, 2000; Schmahmann \& Sherman, 1998). The effects of damage to the cerebellum are often so strongly related to affect and cognition that the associated constellation of symptoms has been described as "dysmetria of thought" (Schmahmann, 2004) and the "cerebellar cognitive affective syndrome" (Schmahmann \& Sherman, 1998). Recent fMRI data also suggest that the cerebellum is important for constructing probabilistic models to aid decision making under conditions of uncertainty (Blackwood et al., 2004) and has been speculated even to play a role in the ability to infer the mental states and intentions of others (Blakemore \& Decety, 2001). When considered in light of existing research on the role of the cerebellum in modulating affect and cognition, as well as its long-established role in complex motor coordination, the present data suggest that the cerebellum may also be an important structure in coordinating complex cognitive and affective processes and that this may contribute directly to an individual's level of EQ.
In addition to total EQ scores, we also conducted an exploratory analysis to more directly examine the correlation of each of the five subscale scores on the Bar-On EQ-i:YV with changes in BOLD signal in response to the fearful faces. Although these subscale scores are less reliable than total EQ, their individual correlations may provide additional understanding of the neurobiology underlying specific aspects of EQ. For instance, positive correlations with the intrapersonal scale, which measures the adolescent's self-awareness of his or her own feelings and the ability to communicate effectively about those feelings, were observed within the precuneus, a region previously shown to be involved in self-awareness (Johnson et al., 2002) and self-related intentionality (den Ouden, Frith, Frith, \& Blakemore, 2005), and within small regions of the visual association cortices, whereas negative correlations were found in the primary sensory-motor cortex and the middle temporal gyrus. In contrast, scores on the interpersonal scale, which measures more outward focus toward relationships with others, showed positive correlations in the left cerebellum and visual association cortices, whereas negative correlations were highly localized to the anterior cingulate gyrus and medial prefrontal cortex. Such findings suggest that adolescents with a high capacity for effective interpersonal relationships show more activity in regions important for complex visual processing and reduced activity in limbic regions often associated with self-referential thinking (Johnson et al., 2002), affective processing, and error detection (Bush, Luu, \& Posner, 2000). Interestingly, scores on the adaptability scale showed no positive correlations with any brain region, whereas negative correlations were found in regions important for face processing, such as the fusiform gyrus and the insula, a region often associated with internal monitoring of emotional and visceral states (Binkofski et al., 1998; Dunckley et al., 2005; Reiman, 1997; Reiman et al., 1997; Vandenbergh et al., 2005), suggesting that increased activation of these regions may be associated with greater difficulty in adapting to new situations. The stress management scale, which measures the child's ability to cope with adversity and to regulate emotion and behavior, was associated with greater activity in the visual association cortex and reduced activity within regions important for monitoring bodily sensations, including the insula and primary somatosensory cortex. Such a pattern would be consistent with increased somatic and visceral sensations in adolescents with greater difficulty in managing stress. Finally, the general mood scale, which measures optimism and a positive approach to situations, was not significantly correlated with brain activity. Although tentative and exploratory in nature, many of these subscale findings are consistent with the known neuroanatomy of affective processing and may shed additional light on the component systems that contribute to the development of EQ in adolescents.

There continues to be some debate as to whether the construct of EQ is psychometrically distinct from that of general cognitive intelligence (Kaufman \& Kaufman, 2001; Roberts, Zeidner, \& Matthews, 2001; Zeidner, Matthews, \& Roberts, 2001), although growing evidence 
appears to support such a position (Mayer et al., 1999; Mayer et al., 2001). The present findings may also contribute to this debate, since they demonstrate that some facets of emotional intelligence are associated with specific patterns of neural activity. A number of functional neuroimaging studies have suggested that traditional constructs of intelligence, such as IQ or general intellectual capacity $(\mathrm{g})$, are associated with distinct regions of brain activity, particularly within the lateral prefrontal cortex (Duncan et al., 2000; Gray, Chabris, \& Braver, 2003), and these prefrontal regions change in volume in a characteristic manner with development from childhood through adolescence (Shaw et al., 2006). Interestingly, these same lateral prefrontal regions were generally unrelated to EQ in the present study. Furthermore, many of the regions that were found to correlate systematically with EQ-i, including limbic and paralimbic structures, have not been highly correlated with general cognitive intelligence in brain-imaging studies, suggesting that EQ appears to involve a number of neural systems that are distinct from those involved in general cognitive intelligence. There were, however, a few regions that appear to be commonly activated across studies as well. These include the medial prefrontal cortex (BA 10), the middle temporal gyrus (BA 21), and the parietal (BA 3) and occipital (BA 19) cortices, which were positively correlated with various EQ scales and have also been shown to correlate with higher IQ (Haier et al., 2004). Although speculative, these findings raise the possibility that both EQ and standard cognitive intelligence may share some core cortical systems in common, while simultaneously drawing upon unique systems that are specific to the type of processing involved. Future functional neuroimaging research may address these hypotheses by including measures of both types of intelligence within the same study.

From the present data, it is not possible to determine whether these relationships are consistent across the adolescent developmental period and remain stable into adulthood or whether they are specific only to the period of adolescence studied. Future studies in which the neurobiological correlates of EQ in adults are examined will provide the opportunity to more fully discriminate those aspects of brain function that change with emotional and social development from those that remain relatively stable across the lifespan. Another important issue is whether the observed correlations differ between male and female children and adolescents. It is well established that girls typically mature faster than boys and will enter puberty about 2 years earlier, on average (Halpern, 2000). Furthermore, considerable research suggests that males and females differ in their emotional perceptiveness (Hall, 1978), in cognitive processing of emotional facial stimuli (Killgore, 2000; Killgore \& Cupp, 2002; Killgore \& Gangestad, 1999), and in the associated brain responses during emotional facial perception (Killgore et al., 2001; Killgore \& Yurgelun-Todd, 2001). Unfortunately, in the present study, sample size constraints prevented further subdivision of the data for the analysis of gender differences. Future investigations in which the neural underpinnings of emotional intelligence are examined may benefit from the use of larger and more diverse samples, including younger children, older adolescents, and adults, as well as direct comparisons between males and females.

The present findings may also be limited by methodological factors, such as the use of a blocked paradigm for stimulus presentation. Previous studies have suggested that the amygdala habituates rapidly in response to repeated presentations of affective stimuli when they are presented continuously in a block paradigm (Breiter et al., 1996; Whalen et al., 1998; C. I. Wright et al., 2001). However, since we were interested only in the correlation between amygdala responses and EQ scores, rather than in differences in amygdala activity due to variability in the affective stimuli used, this issue does not pose a direct threat to the integrity of these data. Furthermore, it is possible that the rate of amygdala habituation may play an important role in emotionally intelligent behavior and should be explored further. These data are also potentially limited by the use of the standard adult brain atlas template from SPM99 for normalizing the functional images obtained from the adolescents. It is not yet clear whether the morphological differences between adolescent brains and those of adults are significant enough to result in severe distortions of the functional neuroimaging data, but such a possibility does exist and, therefore, suggests caution when these findings are interpreted (Wilke, Schmithorst, \& Holland, 2002). Preliminary evidence, however, suggests that the normalization issue may not be problematic, since most adolescent brains are nearly fully developed with regard to total cerebral volume (Caviness, Kennedy, Richelme, Rademacher, \& Filipek, 1996), and that normalization to an adult template is unlikely to produce significant anatomical distortion for the brains of children beyond the age of 6 years (Muzik, Chugani, Juhasz, Shen, \& Chugani, 2000). Until a standard adolescent template brain is available and commonly accepted for such analyses, this potential limitation will remain. The construction of brain templates for child and adolescent samples will undoubtedly advance the ability to study the neurobiological underpinnings of cognitive development, and such projects are encouraged. Finally, we acknowledge the limitations of using a self-report measure of EQ, which may reflect inaccurate self-perceptions and biases. At present, the Bar-On EQ-i:YV is one of the most widely used and psychometrically validated measures of adolescent EQ available, but further research would benefit from the use of alternate measures of the construct of EQ, such as the Mayer-Salovey-Caruso Emotional Intelligence Test (Caruso, Mayer, \& Salovey, 2002; Mayer, Salovey, Caruso, \& Sitarenios, 2003) or others (Brackett \& Mayer, 2003). Confirmation of the present findings with objective measures and alternative instruments will be necessary before strong conclusions about the relationship between the construct of EQ and brain function can be reached. Finally, it should be noted that the present data were obtained with a paradigm involving simple perception of fearful faces. Whether these relationships will generalize to other affective stimuli (e.g., happy faces) or cognitive challenges may be addressed by future research. With the aforementioned limitations in mind, we believe that the 
present data provide important insights into the relationship between activity within the somatic marker circuitry and measured EQ in adolescent children.

\section{CONCLUSION}

During the perception of fearful faces, higher levels of EQ in adolescent children were associated with greater activity in the cerebellum and visual association cortex, as well as with decreased activity in a variety of emotionrelated limbic and paralimbic regions, including the insula, cingulate, ventromedial prefrontal cortex, amygdala, hippocampus, and parahippocampal gyrus. These findings suggest that EQ in adolescent children may involve greater neural efficiency of these key emotionalprocessing structures and, therefore, may lead to reduced reactivity in response to emotional provocation within the somatic marker circuitry believed to mediate the integration of somatic states and cognition during decision making.

\section{AUTHOR NOTE}

This work was supported by a grant from the Hood Foundation to D.A.Y.-T., and by a grant from the National Institute of Child Health and Human Development (NICHD) to W.D.S.K. and D.A.Y.-T., NIH Grant 1R03 HD41542-01. Correspondence concerning this article should be addressed to W. D. S. Killgore, Department of Behavioral Biology, Division of Psychiatry and Neuroscience, Walter Reed Army Institute of Research, 503 Robert Grant Avenue, Silver Spring, MD 20910 (e-mail: killgore@mclean.harvard.edu or william.killgore@na.amedd.army.mil).

\section{REFERENCES}

Abercrombie, H. C., Schaefer, S. M., Larson, C. L., Oakes, T. R., Lindgren, K. A., Holden, J. E., ET AL. (1998). Metabolic rate in the right amygdala predicts negative affect in depressed patients. NeuroReport, 9, 3301-3307.

Anand, A., Li, Y., Wang, Y., Wu, J., Gao, S., Bukhari, L., ET al. (2005). Activity and connectivity of brain mood regulating circuit in depression: A functional magnetic resonance study. Biological Psychiatry, 57, 1079-1088.

Aron, A., Fisher, H., Mashek, D. J., Strong, G., Li, H., \& Brown, L. L. (2005). Reward, motivation, and emotion systems associated with early-stage intense romantic love. Journal of Neurophysiology, 94, 327-337.

Asanuma, C., Thach, W. T., \& Jones, E. G. (1983). Distribution of cerebellar terminations and their relation to other afferent terminations in the ventral lateral thalamic region of the monkey. Brain Research, 286, 237-265.

Baird, A. A., Gruber, S. A., Fein, D. A., Maas, L. C., Steingard, R. J., RenshaW, P. F., ET AL. (1999). Functional magnetic resonance imaging of facial affect recognition in children and adolescents. Journal of the American Academy of Child \& Adolescent Psychiatry, 38, 195-199.

BAR-On, R. (1997). BarOn Emotional Quotient Inventory: A measure of emotional intelligence-Technical Manual. North Tonawanda, NY: Multi-Health Systems.

Bar-On, R., \& Parker, J. D. A. (2000). BarOn Emotional QuotientInventory: Youth Version (BarOn EQ-i:YV). San Francisco: JosseyBass.

Bar-On, R., Tranel, D., Denburg, N. L., \& Bechara, A. (2003). Exploring the neurological substrate of emotional and social intelligence. Brain, 126, 1790-1800.

Bechara, A., Damasio, H., \& Damasio, A. R. (2000). Emotion, decision making and the orbitofrontal cortex. Cerebral Cortex, 10, 295-307.

Bechara, A., Damasio, H., Damasio, A. R., \& Lee, G. P. (1999). Different contributions of the human amygdala and ventromedial prefrontal cortex to decision-making. Journal of Neuroscience, 19, 5473-5481.
Bechara, A., Tranel, D., \& Damasio, H. (2000). Characterization of the decision-making deficit of patients with ventromedial prefrontal cortex lesions. Brain, 123, 2189-2202.

Bergerbest, D., Ghahremani, D. G., \& Gabrieli, J. D. E. (2004). Neural correlates of auditory repetition priming: Reduced fMRI activation in the auditory cortex. Journal of Cognitive Neuroscience, 16, 966-977.

Binkofski, F., Schnitzler, A., Enck, P., Frieling, T., Posse, S., Seitz, R. J., \& Freund, H. J. (1998). Somatic and limbic cortex activation in esophageal distention: A functional magnetic resonance imaging study. Annals of Neurology, 44, 811-815.

Blackwood, N., Ffytche, D., Simmons, A., Bentall, R., Murray, R., $\&$ HowARD, R. (2004). The cerebellum and decision making under uncertainty. Cognitive Brain Research, 20, 46-53.

Blakemore, S. J., \& Decety, J. (2001). From the perception of action to the understanding of intention. Nature Reviews Neuroscience, $\mathbf{2}$, 561-567.

Blonder, L. X., Smith, C. D., Davis, C. E., Kesler-West, M. L., GarRity, T. F., Avison, M. J., \& Andersen, A. H. (2004). Regional brain response to faces of humans and dogs. Cognitive Brain Research, 20, 384-394.

Boucart, M., Meyer, M. E., Pins, D., Humphreys, G. W., Scheiber, C., Gounod, D., \& Foucher, J. (2000). Automatic object identification: An fMRI study. NeuroReport, 11, 2379-2383.

Brackett, M. A., \& MaYer, J. D. (2003). Convergent, discriminant, and incremental validity of competing measures of emotional intelligence. Personality \& Social Psychology Bulletin, 29, 1147-1158.

Breiter, H. C., Etcoff, N. L., Whalen, P. J., Kennedy, W. A., Rauch, S. L., BUCKNER, R. L., ET AL. (1996). Response and habituation of the human amygdala during visual processing of facial expression. Neuron, 17, 875-887.

Breiter, H. C., Gollub, R. L., Weisskoff, R. M., Kennedy, D. N., Makris, N., Berke, J. D., ET AL. (1997). Acute effects of cocaine on human brain activity and emotion. Neuron, 19, 591-611.

Brown, T. T., Lugar, H. M., Coalson, R. S., Miezin, F. M., Petersen, S. E., \& Schlaggar, B. L. (2005). Developmental changes in human cerebral functional organization for word generation. Cerebral Cortex, 15, 275-290.

Buchel, C., Morris, J., Dolan, R. J., \& Friston, K. J. (1998). Brain systems mediating aversive conditioning: An event-related fMRI study. Neuron, 20, 947-957.

Bush, G., LuU, P., \& Posner, M. I. (2000). Cognitive and emotional influences in anterior cingulate cortex. Trends in Cognitive Sciences, 4, 215-222.

Caruso, D. R., Mayer, J. D., \& Salovey, P. (2002). Relation of an ability measure of emotional intelligence to personality. Journal of Personality Assessment, 79, 306-320.

Caviness, V. S., JR., Kennedy, D. N., Richelme, C., Rademacher, J., $\&$ FiliPEK, P. A. (1996). The human brain age 7-11 years: A volumetric analysis based on magnetic resonance images. Cerebral Cortex, 6, 726-736.

Christakou, A., Robbins, T. W., \& Everitt, B. J. (2004). Prefrontal cortical-ventral striatal interactions involved in affective modulation of attentional performance: Implications for corticostriatal circuit function. Journal of Neuroscience, 24, 773-780.

Costa, P. T., JR., \& McCrae, R. R. (1992). Revised NEO Personality Inventory (NEO-PI-R) and NEO Five-Factor Inventory (NEO-FFI) professional manual. Odessa, FL: Psychological Assessment Resources.

Damasio, A. R. (1994). Descartes' error: Emotion, reason, and the human brain. New York: Grosset/Putnam.

Damasio, A. R. (1996). The somatic marker hypothesis and the possible functions of the prefrontal cortex. Philosophical Transactions of the Royal Society of London: Series B, 351, 1413-1420.

DAWDA, D., \& HART, S. D. (2000). Assessing emotional intelligence: Reliability and validity of the Bar-On Emotional Quotient Inventory (EQ-i) in university students. Personality \& Individual Differences, 28, 797-812.

den Ouden, H. E., Frith, U., Frith, C., \& Blakemore, S. J. (2005). Thinking about intentions. NeuroImage, 28, 787-796.

D’Esposito, M., Detre, J. A., Aguirre, G. K., Stallcup, M., Alsop, D. C., TIPPET, L. J., \& FARAH, M. J. (1997). A functional MRI study of mental image generation. Neuropsychologia, 35, 725-730.

Drevets, W. C. (1999). Prefrontal cortical-amygdalar metabolism in 
major depression. In J. F. McGinty (Ed.), Advancing from the ventral striatum to the extended amygdala: Implications for neuropsychiatry and drug abuse (Annals of the New York Academy of Sciences, Vol. 877, pp. 614-637). New York: New York Academy of Sciences.

Duncan, J., Seitz, R. J., Kolodny, J., Bor, D., Herzog, H., Ahmed, A., ET AL. (2000). A neural basis for general intelligence. Science, 289, 457-460.

Dunckley, P., Wise, R. G., Aziz, Q., Painter, D., Brooks, J., Tracey, I., \& Chang, L. (2005). Cortical processing of visceral and somatic stimulation: Differentiating pain intensity from unpleasantness. Neuroscience, 133, 533-542.

Durston, S., Davison, M. C., Tottenham, N., Galvan, A., Spicer, J. A., Fossella, F., \& CASEY, B. J. (2006). A shift from diffuse to focal cortical activity with development. Developmental Science, 9, 1-8.

Ekman, P., \& Friesen, W. V. (1976). Pictures of facial affect. Palo Alto, CA: Consulting Psychologists Press.

Exner, C., Weniger, G., \& IrLe, E. (2004). Cerebellar lesions in the PICA but not SCA territory impair cognition. Neurology, 63, 2132-2135.

Fredrikson, M., \& Furmark, T. (2003). Amygdaloid regional cerebral blood flow and subjective fear during symptom provocation in anxiety disorders. In P. Shinnick-Gallagher, A. Pitkänen, A. Shekhar, \& L. Cahill (Eds.), The amygdala in brain function: Basic and clinical approaches (Annals of the New York Academy of Sciences, Vol. 985, pp. 341-347). New York: New York Academy of Sciences.

Friston, K. J., Holmes, A. P., Worsley, K. J., Poline, J.-P., Frith, C. D., \& FrackowiaK, R. S. J. (1995). Statistical parametric maps in functional imaging: A general linear approach. Human Brain Mapping, 2, 189-210.

Furmark, T., Fischer, H., Wik, G., Larsson, M., \& Fredrikson, M. (1997). The amygdala and individual differences in human fear conditioning. NeuroReport, 8, 3957-3960.

Ghez, C., \& FaHn, S. (1985). The cerebellum. In E. R. Kandel \& J. H. Schwartz (Eds.), Principles of neural science (2nd ed., pp. 502-522). New York: Elsevier.

Goleman, D. (1995). Emotional intelligence. New York: Bantam.

Gray, J. R., Chabris, C. F., \& Braver, T. S. (2003). Neural mechanisms of general fluid intelligence. Nature Neuroscience, 6, 316-322.

Haier, R. J., Jung, R. E., Yeo, R. A., Head, K., \& Alkire, M. T. (2004). Structural brain variation and general intelligence. NeuroImage, 23, 425-433.

Haier, R. J., Siegel, B. V., Maclachlan, A., Soderling, E., LottenBERG, S., \& Buchsbaum, M. S. (1992). Regional glucose metabolic changes after learning a complex visuospatial/motor task: A positron emission tomographic study. Brain Research, 570, 134-143.

Haier, R. J., Siegel, B. V., Tang, C., Abel, L., \& Buchsbaum, M. S. (1992). Intelligence and changes in regional cerebral glucose metabolic rate following learning. Intelligence, 16, 415-426.

Hall, J. A. (1978). Gender effects in decoding nonverbal cues. Psychological Bulletin, 85, 845-857.

Halpern, D. F. (2000). Sex differences in cognitive abilities (3rd ed.). Mahwah, NJ: Erlbaum.

Haslinger, B., Erhard, P., Altenmüller, E., Hennenlotter, A., Schwaiger, M., vON EInsiedel, H. G., ET AL. (2004). Reduced recruitment of motor association areas during bimanual coordination in concert pianists. Human Brain Mapping, 22, 206-215.

Johnson, S. C., Baxter, L. C., Wilder, L. S., Pipe, J. G., Heiserman, J. E., \& Prigatano, G. P. (2002). Neural correlates of self-reflection. Brain, 125, 1808-1814.

Kaufman, A. S., \& Kaufman, J. C. (2001). Emotional intelligence as an aspect of general intelligence: What would David Wechsler say? Emotion, 1, 258-264.

Keedwell, P. A., Andrew, C., Williams, S. C., Brammer, M. J., \& Phillips, M. L. (2005). The neural correlates of anhedonia in major depressive disorder. Biological Psychiatry, 58, 843-853.

KILLGORE, W. D. S. (2000). Sex differences in identifying the facial affect of normal and mirror-reversed faces. Perceptual \& Motor Skills, 91, 525-530.

Killgore, W. D. S., \& Cupp, D. W. (2002). Mood and sex of participant in perception of happy faces. Perceptual \& Motor Skills, 95, 279-288.

Killgore, W. D. S., \& Gangestad, S. W. (1999). Sex differences in asymmetrically perceiving the intensity of facial expressions. Perceptual \& Motor Skills, 89, 311-314.

Killgore, W. D. S., OKi, M., \& Yurgelun-Todd, D. A. (2001). Sexspecific developmental changes in amygdala responses to affective faces. NeuroReport, 12, 427-433.

Killgore, W. D. S., \& Yurgelun-Todd, D. A. (2001). Sex differences in amygdala activation during the perception of facial affect. NeuroReport, 12, 2543-2547.

Killgore, W. D. S., \& Yurgelun-Todd, D. A. (2005). Social anxiety predicts amygdala activation in adolescents viewing fearful faces. NeuroReport, 16, 1671-1675.

Killgore, W. D. S., \& Yurgelun-Todd, D. A. (2006). Ventromedial prefrontal activity correlates with depressed mood in adolescent children. NeuroReport, 17, 167-171.

KLoep, M. (1999). Love is all you need? Focusing on adolescents' life concerns from an ecological point of view. Journal of Adolescence, 22, 49-63.

Lee, G. P., Meador, K. J., Loring, D. W., Allison, J. D., Brown, W. S., PAUL, L. K., ET AL. (2004). Neural substrates of emotion as revealed by functional magnetic resonance imaging. Cognitive $\& \mathrm{Be}-$ havioral Neurology, 17, 9-17.

Levy, R., \& Dubois, B. (2006). Apathy and the functional anatomy of the prefrontal cortex-basal ganglia circuits. Cerebral Cortex, 16, 916-928.

Lorberbaum, J. P., Kose, S., Johnson, M. R., Arana, G. W., SulliVAN, L. K., HAMNER, M. B., ET AL. (2004). Neural correlates of speech anticipatory anxiety in generalized social phobia. NeuroReport, 15, 2701-2705.

Maldjian, J. A., Laurienti, P. J., Kraft, R. A., \& Burdette, J. H. (2003). An automated method for neuroanatomic and cytoarchitectonic atlas-based interrogation of fMRI data sets. NeuroImage, 19, 1233-1239.

MAYBERG, H. S. (1997). Limbic-cortical dysregulation: A proposed model of depression. Journal of Neuropsychiatry \& Clinical Neurosciences, 9, 471-481.

Mayberg, H. S., Liotti, M., Brannan, S. K., McGinnis, S., Mahurin, R. K., JERABEK, P. A., ET AL. (1999). Reciprocal limbic-cortical function and negative mood: Converging PET findings in depression and normal sadness. American Journal of Psychiatry, 156, 675-682.

Mayer, J. D., Caruso, D. R., \& Salovey, P. (1999). Emotional intelligence meets traditional standards for an intelligence. Intelligence, 27, 267-298

Mayer, J. D., DiPaolo, M., \& Salovey, P. (1990). Perceiving affective content in ambiguous visual stimuli: A component of emotional intelligence. Journal of Personality Assessment, 54, 772-781.

Mayer, J. D., Salovey, P., Caruso, D. R., \& Sitarenios, G. (2001). Emotional intelligence as a standard intelligence. Emotion, 1, 232-242.

Mayer, J. D., Salovey, P., Caruso, D. R., \& Sitarenios, G. (2003). Measuring emotional intelligence with the MSCEIT V2.0. Emotion, 3, 97-105.

Middleton, F. A., \& Strick, P. L. (1994). Anatomical evidence for cerebellar and basal ganglia involvement in higher cognitive function. Science, 266, 458-461.

Muzik, O., Chugani, D. C., Juhasz, C., Shen, C., \& Chugani, H. T. (2000). Statistical parametric mapping: Assessment of application in children. NeuroImage, 12, 538-549.

Nelson, E. E., Leibenluft, E., McClure, E. B., \& Pine, D. S. (2005). The social re-orientation of adolescence: A neuroscience perspective on the process and its relation to psychopathology. Psychological Medicine, 35, 163-174

Olson, I. R., Rao, H., Moore, K. S., Wang, J., Detre, J. A., \& Aguirre, G. K. (2006). Using perfusion fMRI to measure continuous changes in neural activity with learning. Brain \& Cognition, 60, 262-271.

Paulus, M. P., Feinstein, J. S., Castillo, G., Simmons, A. N., \& Stein, M. B. (2005). Dose-dependent decrease of activation in bilateral amygdala and insula by lorazepam during emotion processing. Archives of General Psychiatry, 62, 282-288.

Penny, W. D., Holmes, A. P., \& Friston, K. J. (2003). Random effects analysis. In R. S. J. Frackowiak, K. J. Friston, C. Frith, R. Dolan, C. J. Price, S. Zeki, et al. (Eds.), Human brain function (2nd ed., pp. 843850). San Diego: Academic Press. 
Phillips, M. L., Young, A. W., Senior, C., Brammer, M., Andrew, C., CALder, A. J., ET AL. (1997). A specific neural substrate for perceiving facial expressions of disgust. Nature, 389, 495-498.

Poldrack, R. A., Desmond, J. E., Glover, G. H., \& Gabrieli, J. D. E. (1998). The neural basis of visual skill learning: An fMRI study of mirror reading. Cerebral Cortex, 8, 1-10.

Rauch, S. L., Whalen, P. J., Shin, L. M., McInerney, S. C., Macklin, M. L., LASKO, N. B., ET AL. (2000). Exaggerated amygdala response to masked facial stimuli in posttraumatic stress disorder: A functional MRI study. Biological Psychiatry, 47, 769-776.

Ray, R. D., Ochsner, K. N., Cooper, J. C., Robertson, E. R., GaBRIELI, J. D. E., \& Gross, J. J. (2005). Individual differences in trait rumination and the neural systems supporting cognitive reappraisal. Cognitive, Affective, \& Behavioral Neuroscience, 5, 156-168.

ReIman, E. M. (1997). The application of positron emission tomography to the study of normal and pathologic emotions. Journal of Clinical Psychiatry, 58, 4-12.

Reiman, E. M., Lane, R. D., Ahern, G. L., Schwartz, G. E., DavidSON, R. J., FRISTON, K. J., ET AL. (1997). Neuroanatomical correlates of externally and internally generated human emotion. American Journal of Psychiatry, 154, 918-925.

Rissman, J., Eliassen, J. C., \& Blumstein, S. E. (2003). An eventrelated fMRI investigation of implicit semantic priming. Journal of Cognitive Neuroscience, 15, 1160-1175.

Riva, D., \& Giorgi, C. (2000). The cerebellum contributes to higher functions during development: Evidence from a series of children surgically treated for posterior fossa tumours. Brain, 123, 1051-1061.

Roberts, R. D., Zeidner, M., \& Matthews, G. (2001). Does emotional intelligence meet traditional standards for an intelligence? Some new data and conclusions. Emotion, 1, 196-231.

Sakai, Y., Kumano, H., Nishikawa, M., Sakano, Y., Kaiya, H., IMABAYASHI, E., ET AL. (2005). Cerebral glucose metabolism associated with a fear network in panic disorder. NeuroReport, 16, 927-931.

SchmahmanN, J. D. (1991). An emerging concept: The cerebellar contribution to higher function. Archives of Neurology, 48, 1178-1187.

Schmahmann, J. D. (2004). Disorders of the cerebellum: Ataxia, dysmetria of thought, and the cerebellar cognitive affective syndrome. Journal of Neuropsychiatry \& Clinical Neuroscience, 16, 367-378.

Schmahmann, J. D., \& Sherman, J. C. (1998). The cerebellar cognitive affective syndrome. Brain, 121, 561-579.

Shamay-Tsoory, S. G., Lester, H., Chisin, R., Israel, O., BarShalom, R., Peretz, A., Et Al. (2005). The neural correlates of understanding the other's distress: A positron emission tomography investigation of accurate empathy. NeuroImage, 27, 468-472.

Shaw, P., Greenstein, D., Lerch, J., Clasen, L., Lenroot, R., GogTAY, N., ET AL. (2006). Intellectual ability and cortical development in children and adolescents. Nature, 440, 676-679.

SHULER, C. N. (2005). An analysis of the Emotional Quotient Inventory: Youth version as a measure of emotional intelligence in children and adolescents. Dissertation Abstracts International, 65, 2492.

Spear, L. P. (2000). The adolescent brain and age-related behavioral manifestations. Neuroscience \& Biobehavioral Reviews, 24, 417-463.
Straube, T., Mentzel, H. J., \& Miltner, W. H. (2006). Neural mechanisms of automatic and direct processing of phobogenic stimuli in specific phobia. Biological Psychiatry, 59, 162-170.

Tamm, L., Menon, V., \& Reiss, A. L. (2002). Maturation of brain function associated with response inhibition. Journal of the American Academy of Child \& Adolescent Psychiatry, 41, 1231-1238.

Teasdale, J. D., Howard, R. J., Cox, S. G., Ha, Y., Brammer, M. J., Williams, S. C. R., \& CHECKLEY, S. A. (1999). Functional MRI study of the cognitive generation of affect. American Journal of Psychiatry, 156, 209-215

Tomasi, D., Ernst, T., Caparelli, E. C., \& Chang, L. (2004). Practiceinduced changes of brain function during visual attention: A parametric fMRI study at 4 Tesla. NeuroImage, 23, 1414-1421.

Tzourio-Mazoyer, N., Landeau, B., Papathanassiou, D., Crivello, F., Etard, O., Delcroix, N., et al. (2002). Automated anatomical labeling of activations in SPM using a macroscopic anatomical parcellation of the MNI MRI single-subject brain. NeuroImage, 15, 273-289.

Vaina, L. M., Solomon, J., Chowdhury, S., Sinha, P., \& Belliveau, J. W. (2001). Functional neuroanatomy of biological motion perception in humans. Proceedings of the National Academy of Sciences, 98, 11656-11661

Vandenbergh, J., Dupont, P., Fischler, B., Bormans, G., Persoons, P., JANSSENS, J., \& TACK, J. (2005). Regional brain activation during proximal stomach distention in humans: A positron emission tomography study. Gastroenterology, 128, 564-573.

Whalen, P. J., Rauch, S. L., Etcoff, N. L., McInerney, S. C., Lee, M. B., \& JeNIKE, M. A. (1998). Masked presentations of emotional facial expressions modulate amygdala activity without explicit knowledge. Journal of Neuroscience, 18, 411-418.

Wilke, M., Schmithorst, V. J., \& Holland, S. K. (2002). Assessment of spatial normalization of whole-brain magnetic resonance images in children. Human Brain Mapping, 17, 48-60.

Wright, C. I., Fischer, H., Whalen, P. J., McInerney, S. C., Shin, L. M., \& RaUCH, S. L. (2001). Differential prefrontal cortex and amygdala habituation to repeatedly presented emotional stimuli. NeuroReport, 12, 379-383.

Wright, P., He, G., Shapira, N. A., Goodman, W. K., \& LiU, Y. (2004). Disgust and the insula: fMRI responses to pictures of mutilation and contamination. NeuroReport, 15, 2347-2351.

Yurgelun-Todd, D. A., Gruber, S. A., Kanayama, G., Killgore, W. D. S., BAIRD, A. A., \& Young, A. D. (2000). fMRI during affect discrimination in bipolar affective disorder. Bipolar Disorders, 2, 237-248.

Zeidner, M., Matthews, G., \& Roberts, R. D. (2001). Slow down, you move too fast: Emotional intelligence remains an "elusive" intelligence. Emotion, 1, 265-275.

(Manuscript received May 10, 2006; revision accepted for publication November 20, 2006.) 